\section{Commentary: Unraveling the secrets of the neglected tricuspid valve}

\author{
Shuab Omer, MD
}

Despite being dubbed as the forgotten valve, there has emerged a growing body of evidence highlighting the adverse impact of untreated tricuspid regurgitation (TR) in patients undergoing left sided heart valve surgery. Based on this, the current American Heart Association/American College of Cardiology ${ }^{1}$ and European Society of Cardiology/European Association for Cardio-Thoracic Surgery ${ }^{2}$ guidelines recommend concomitant tricuspid repair for both severe TR (Class I) as well as mild or moderate functional TR if tricuspid annular diameter is $\geq 40 \mathrm{~mm}$ for patients undergoing left-sided valve surgery (Class IIa, Level of Evidence B). These guidelines are far from perfect, owing to large knowledge gaps regarding the etiology and natural history of secondary TR.

Most studies to date have lumped together all the leftsided valvular lesions, assuming that the resulting secondary TR has the same pathogenesis and natural history irrespective of whether the primary left-sided disease is DMD (degenerative mitral disease), functional mitral regurgitation, mitral stenosis, aortic stenosis, etc. Such assumptions could be misleading and might be a major source of bias. The guidelines further fail to specify the impact of comorbidities like preoperative atrial fibrillation (AF) on the progression of TR and survival.

In the current issue of the Journal, McCarthy and colleagues $^{3}$ have demonstrated that concomitant tricuspid valve (TV) repair during mitral valve (MV) surgery might not be of benefit unless the tricuspid annular diameter is $\geq 45 \mathrm{~mm}$ instead of the $\geq 40 \mathrm{~mm}$ threshold per current guidelines and for patients with AF there is a significant, steadily increasing, and heretofore-unrecognized risk of late TR even with concomitant AF ablation.

\footnotetext{
From the Department of Advanced Cardiopulmonary Therapies and Transplantation, The University of Texas Health Science Center at Houston, McGovern Medical School, Houston, Tex.

Disclosures: Author has nothing to disclose with regard to commercial support.

Received for publication Nov 29, 2019; revisions received Nov 29, 2019; accepted for publication Nov 29, 2019; available ahead of print Dec 14, 2019.

Address for reprints: Shuab Omer, MD, Department of Advanced Cardiopulmonary Therapies and Transplantation, The University of Texas Health Science Center at Houston, McGovern Medical School, Houston, TX 77030 (E-mail: shuab.omer@ uth.thc.edu).

J Thorac Cardiovasc Surg 2021;161:2041-2

0022-5223/\$36.00

Copyright (C) 2019 by The American Association for Thoracic Surgery

https://doi.org/10.1016/j.jtcvs.2019.11.116
}

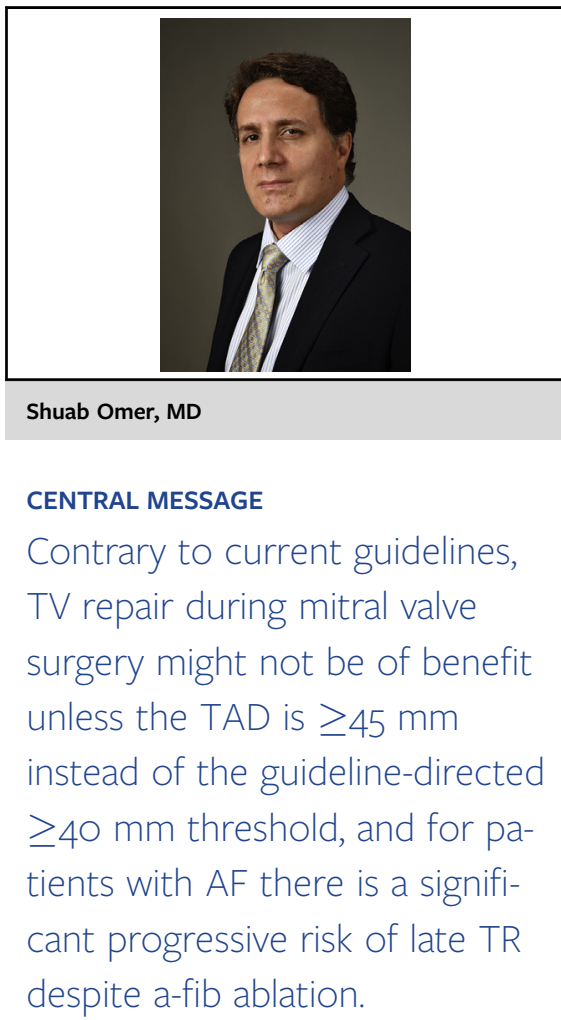

At first glance, it seems puzzling why the study by McCarthy and colleagues ${ }^{3}$ failed to show progression of TR in the subset of patients with a tricuspid annulus 40 to $45 \mathrm{~mm}$ in contrast to the $\geq 40 \mathrm{~mm}$ threshold per current guidelines. A likely answer could be that unlike previous studies, the current study focuses purely on DMD rather than all left-sided lesions and thus might be more reflective of the natural history of TR in DMD. Thus, it is compelling to suggest that future studies on this subject should focus on teasing out the subtle differences between subtypes of concomitant mitral and tricuspid disease. However, it is also plausible that in the current study the benefit of operating on guideline-directed lower threshold of $\geq 40 \mathrm{~mm}$ may have been missed, as late follow-up echo was available for just $40 \%$ of patients, mean interval from index operation to follow-up echo was just $4.0 \pm 3.3$ years, a significant number (212) patients did not have the recommended apical views for evaluating the TV, and finally follow-up echos were done randomly based on wishes of the cardiologist.

From a practical standpoint in the current era, adding TV surgery during MV procedures in valve centers of excellence does not significantly add to the mortality and morbidity, ${ }^{4}$ whereas the operative mortality of redo TV repair has a mortality as high as $35 \%{ }^{5}$ and hence it begs the question whether it is prudent to risk following a more 
restrictive $\geq 45 \mathrm{~mm}$ threshold rather than the guidelinedirected liberal $\geq 40 \mathrm{~mm}$ ?

The current study further demonstrates the lingering impact of comorbid AF on progression of TR after MV surgery despite a high percentage of patients $(97 \%)$ receiving surgical maze procedure and despite a high percentage $(87 \%)$ of patients free of AF on follow-up. These results are hard to ignore despite the various sources of bias accepted by the authors, and it seems reasonable to be more aggressive in proceeding with concomitant TV repair during MV repair in patients with AF. However, it is worth emphasizing that the study fails to define a clear size threshold for concomitant intervention on the TV in patients with AF or whether it should be done irrespective of annular diameter.

In conclusion, further work needs to be done to define the optimal size threshold for TV intervention in the subgroup of patients with secondary TR with AF, and furthermore there is a need for well-designed randomized studies to weed out the controversies of TV repair during MV surgery, especially in the current era of rapidly evolving and effective percutaneous valve therapies.

\section{References}

1. Nishimura RA, Otto CM, Bonow RO, Carabello BA, Erwin JP III, Guyton RA, et al. 2014 AHA/ACC guideline for the management of patients with valvular heart disease: a report of the American College of Cardiology/American Heart Association task force on practice guidelines. J Am Coll Cardiol. 2014;63:e57-185.

2. Vahanian A, Alfieri O, Andreotti F, Antunes MJ, Barón-Esquivias G, Baumgartner $\mathrm{H}$, et al. Guidelines on the management of valvular heart disease (version 2012): the joint task force on the management of valvular heart disease of the European Society of Cardiology (ESC) and the European Association for Cardio-Thoracic Surgery (EACTS). Eur J Cardiothorac Surg. 2012;42:S1-44.

3. McCarthy PM, Szlapka M, Kruse J, Kislitsina ON, Thomas JD, Liu M, et al. The relationship of atrial fibrillation and tricuspid annular dilation to late tricuspid regurgitation in degenerative mitral repair patients. J Thorac Cardiovasc Surg. 2021;161:2030-40.e3.

4. Badhwar V, Rankin JS, He M, Jacobs JP, Furnary AP, Fazzalari FL, et al. Performing concomitant tricuspid valve repair at the time of mitral valve operations is not associated with increased operative mortality. Ann Thorac Surg. 2017;103:587-93.

5. Bernal JM, Morales D, Revuelta C, Llorca J, Gutierrez-Morlote J, Revuelta JM. Reoperations after tricuspid valve repair. J Thorac Cardiovasc Surg. 2005;130:498-503.
See Article page 2030.

\section{Commentary: Late tricuspid valve insufficiency following mitral valve repair: A marker or a cause for inferior outcome?}

\author{
Niv Ad, MD, a,b and James S. Gammie, MD ${ }^{\mathrm{a}}$
}

The ongoing debate on the appropriate surgical approach to patients with moderate or less tricuspid valve regurgitation at the time of mitral valve (MV) repair for degenerative disease is far from being resolved. This is not because of lack of extensive observational research, it is simply due to the

\footnotetext{
From the a Division of Cardiac Surgery, University of Maryland School of Medicine, Baltimore; and ${ }^{\mathrm{b}}$ Thoracic and Cardiac Surgery, Adventist HealthCare White Oak Medical Center, Silver Spring, Md.

Disclosures: Dr Ad is a consultant for Medtronic, a member of the speaker's bureau for AtriCure, a proctor and member of the speaker's bureau for LivaNova, on the advisory board for Nido Surgical, and co-owner for LeftAtrial Appendage Occlusion, LLC. Dr Gammie is a consultant to Edwards Lifesciences.

Received for publication Dec 16, 2019; revisions received Dec 16, 2019; accepted for publication Dec 16, 2019; available ahead of print Jan 7, 2020.

Address for reprints: Niv Ad, MD, Division of Cardiac Surgery, University of Maryland School of Medicine, 110 S Paca St, 7th Floor, Baltimore, MD 21201 (E-mail: nivadmd14@gmail.com).

J Thorac Cardiovasc Surg 2021;161:2042-4

$0022-5223 / \$ 36.00$

Copyright $($ c 2020 by The American Association for Thoracic Surgery

https://doi.org/10.1016/j.jtcvs.2019.12.053
}

Check for updates

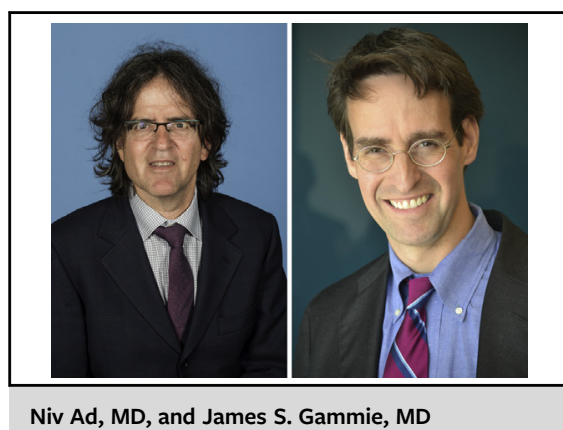

CENTRAL MESSAGE

In this issue, the contribution of

McCarthy and colleagues to the

field is significant. They highlight

the importance of $\mathrm{AF}$, even when

treated effectively, as a risk factor

for recurrent TR.

fact that the clinical question of whether and when to repair a leaking tricuspid valve (TV) at the time of surgery is very complex to answer and the current tools and evidence we 